\title{
Letters
}

Website: www.bmj.com

Email: letters@bmj.com

\section{Caring for and about acute general medicine}

\section{Expansion in consultant numbers is} needed

EDITOR-Forgacs's review provides an excellent picture of the unpleasant reality of acute medicine, as practised at present. ${ }^{1}$ The Royal College of Physicians is well aware of the need to cost future improvements in increasing the number of hospital doctors and to provide evidence of the likely benefits. The latter will be a difficult task but must be tackled. Indeed, a working group of the three Royal Colleges of Physicians is currently reviewing all aspects of the problems regarding acute medicine.

As chairman of the group which produced the document "Consultant physicians working for patients" and main author, ${ }^{2}$ I (JDW) can assure readers that I have had experience, on many occasions, of handling more than 20 acutely ill patients during a 24 hour period of acute medicine as a general physician in Sheffield. Our working group realises that hundreds more consultants tomorrow and much smaller numbers of "take patients" is unrealistic. We do know from several sources that doctors are working 14-16 sessions per week and close to a 60 hour week. We know that consultation times in outpatient departments have been pared to the bone. We know that clinical governance in all its guises will place further demands on consultants. If we do not state our requirements now for an expansion in the number of consultants we will never achieve improvements.

\section{K G M M Alberti President}

J D Ward Vice president

Royal College of Physicians of London, London NW1 4LE

1 Forgacs I. Caring for and about acute general medicine. BMJ 1999;318:73-4. (9 January)

2 Alberti KGMM, Bell J, Goodman M, London D, Wales J Ward JD. Consultant physicians working for patients. Part I: a blueprint for effective hospital practice. $J R$ Coll Physicians Lond 1998;32:suppl.

\section{Specialists should not be expected to practise general medicine}

EDITOR-Forgacs says that there is a pressing need to evaluate the quality of emergency medical care and the demands it makes on those who deliver it.

I retired from the NHS almost seven years ago. My official title was consultant physician and gastroenterologist, and throughout my career as a consultant I took my turn on the on-take rota. However, I stopped seeing general medical patients in outpatients many years ago and over time felt increasingly insecure regarding my non-gastroenterological inpatients. I can only hope that, largely owing to the input of a succession of very well informed medical registrars, the general medical patients who were admitted in my name received better than average care.

I am saying nothing new when I suggest that with the need for specialists to know more and more they cannot do justice to the general field where over time they will inevitably know less and less. It is unrealistic to believe otherwise.

It is unfair to specialist consultants and to their patients to continue to expect the former to practise general medicine, and to admit such patients as part of their on-call responsibilities. There are alternative approaches.

KFR Schiller Emeritus consultant The Mill, Cuddesdon, Oxford OX44 9HQ

1 Forgacs I. Caring for and about acute general medicine BMJ 1999;318:73-4. (9 January.)

\section{Imaginative solutions are required}

EDITOR-I disagree with Forgacs's comments relating to partial shifts. ${ }^{1}$ The Royal College of Physicians's survey revealed general dissatisfaction with partial shifts, but the survey was carried out in 1997 and reflects the period before this, when many partial shifts were in their infancy. ${ }^{2} \mathrm{My}$ own experience of a partial shift was much more positive, with the morale of both junior and senior doctors remaining high despite typically large numbers of admissions. Importantly, our partial shift had been in place for several years and was implemented and subsequently adjusted with input from consultants and juniors. Support for the view that partial shifts, like good wine, can improve with age comes from a recent study by Kapur.

Forgacs cites a frequent criticism of partial shifts, that they reduce continuity and consequently the quality of care. True continuity of care would require an individual or team of doctors to provide cover 24 hours a day, 365 days a year. Currently, under the traditional rota system, patients are looked after by a small number of junior doctors for about $70 \%$ of the time. These doctors are unlikely to have met or discussed most patients before taking over their care. Consequently, I question whether continuity of care has ever existed. Would a system involving defined periods of care with structured hand-over not be better?
Despite the good intentions behind "continuity of care" our reluctance to abandon this mythical concept is limiting our ability to deliver acute medical care in the most efficient way. Only by ridding ourselves of the "continuity of care albatross" can doctors meet the challenge of providing a high quality acute medical service while coping with the changes outlined by Forgacs. Imaginative solutions, including partial shifts, should be considered when the long overdue national audit of emergency medical care finally takes place.

Ian S Shaw Specialist registrar in general medicine and gastroenterology

Cheltenham General Hospital, Cheltenham GL53 7AN

ian@wbuckland.demon.co.uk

1 Forgacs I. Caring for and about acute general medicine. BMJ 1999;318:73-4. (9 January.)

2 Mather HM. Coping with pressures in acute medicine. The Royal College of Physicians questionnaire survey. J R Coll Physicians Lond 1998;32:211-8.

3 Kapur N, House A. Improving new deal shifts for junior house officers. Hospital Medicine 1998;59:960-6.

\section{Where does emergency medicine fit in?}

EDITOR-The new specialty of "acute" medicine seems to have developed overnightbut Forgacs's editorial implies that this role does not suit many traditional medical consultants, especially those whose "main specialty" lies in a narrower area of practice.

\section{Advice to authors}

We prefer to receive all responses electronically, sent either directly to our website or to the editorial office as email or on a disk. Processing your letter will be delayed unless it arrives in an electronic form.

We are now posting all direct submissions to our website within 72 hours of receipt and our intention is to post all other electronic submissions there as well. All responses will be eligible for publication in the paper journal.

Responses should be under 400 words and relate to articles published in the preceding month. They should include $\leqslant 5$ references, in the Vancouver style, including one to the BMJ article to which they relate. We welcome illustrations.

Please supply each author's current appointment and full address, and a phone or fax number or email address for the corresponding author. We ask authors to declare any competing interest. Please send a stamped addressed envelope if you would like to know whether your letter has been accepted or rejected.

Letters will be edited and may be shortened.

www.bmj.com

letters@bmj.com 
Where does emergency medicine fit in? In Australasia this is the fastest growing specialty, with a strong identity and clear goals. It attracts and trains excellent young doctors who identify that their long term career will involve full shift work, as consultants readily available around the clock, diagnosing and treating medical as well as traumatic emergencies.

I suggest that those physicians who are dedicated to providing a good general medical inpatient service should ally themselves to emergency specialists when planning for the future. In particular, the concept of the acute "medical" receiving ward that is at a distance from the emergency department yet accepts patients by ambulance is an anachronism and unnecessarily duplicates and stretches resources.

Acute medicine and emergency medicine are the same thing. Or is this too obvious to state?

John A Chambers Director of emergency medicine training

Dunedin Hospital, Dunedin, New Zealand

johnch@healthotago.co.nz

1 Forgacs I. Caring for and about acute general medicine BMJ 1999;318:73-4. (9 January.)

\section{Consultants should think laterally about} problems within existing work patterns

EDITOR-Forgacs states that $42 \%$ of consultants in medicine work with juniors on shift systems and that a survey by the Royal College of Physicians found that consultants think little of an arrangement perceived as failing to provide real continuity of care. ${ }^{1}$ This perception, apparently supported by most consultants, is based on myth. Because of the large number of emergency admissions, many trusts now have admission units. There, patients are assessed and then sent for further care to various consultant teams, often according to specialty or the availability of beds. In this situation, work pattern is irrelevant to continuity of care.

Rather than cling to the outdated notion that continuity of care means being on duty every day plus overnight-a practice that is proved to be detrimental to patients' care $^{2}$ (particularly in acute general medicine, which is now the busiest specialty)consultants could think laterally and tackle problems concerning continuity of care within existing work patterns. These problems include the lack of good medical record keeping and formal handovers among junior medical staff and the introduction of several badly designed partial shifts.

Nicola Cooper Senior house officer in general medicine

Bradford Hospitals NHS Trust, Bradford Royal infirmary, Bradford BD9 6RJ

Dnacooper@aol.com

1 Forgacs I. Caring for and about acute general medicine. BMJ 1999;318:73-4. (9 January.)

2 Dawson D, Reade K. Fatigue, alcohol and performance. Nature 1997;388:235.

\section{Developments have been made on cardiac surgical audit in Bristol}

EDITOR-The cardiac surgical community is trying to address some of Shortis and Winkler's concerns about the Bristol affair.

Congenital cardiac surgery represents a tenth of cardiac surgery in the United Kingdom. Its complexity and small numbers make individual surgical audit difficult However, the Society of Cardiothoracic Surgeons of Great Britain and Ireland has defined repair of aortic coarctation and ventriculoseptal defect as surgeon specific marker operations for congenital cardiac surgery. Throughout the United Kingdom in 1997-8, 238 operations for simple coarctation were performed by 27 surgeons, with only one death. Similarly, 302 operations for isolated ventriculoseptal defect were performed by a slightly different group of 27 surgeons, with only two deaths. The list has been extended to seven marker operations for 1998-9.

Isolated, first time coronary artery bypass surgery has been defined as a surgeon specific marker operation for adult surgery. Last year, 1997-8, 171 surgeons performed an average of 139 such operations, with an operative mortality of $2.3 \%$ (95\% confidence interval $2.04 \%$ to $2.63 \%$ ).

All NHS units have returned to the society annual activity and mortality data on a large number of procedures since 1977.2 Last year was the first time that all surgeons in the United Kingdom returned these data on specific marker operations. The data provide an effective alarm mechanism, which, in the absence of risk stratification, is likely to be oversensitive. To identify potential problems early we have limited the timescale for submission of data to three months after the end of the financial year. This allows time for all deaths to be captured and for internal validation of data before submission. The results are screened by the society's standards of care committee, and mechanisms have been put in place to review independently the surgical activity of apparent outliers

Bristol Royal Infirmary should be congratulated on the publication of its comprehensive risk stratified data on its website (www.bht.org.uk). This is based on the dataset recommended by the Society of Cardiothoracic Surgeons and adopted by over half the 35 units performing adult cardiac surgery in the United Kingdom, not just the five units that Shortis and Winkler mention. ${ }^{1}$ Our society encourages all units to collect these data to facilitate effective risk stratification, and we expect that next year, 1998-9, the number of units submitting comprehensive data will have risen to over $80 \%$. We agree that this does not need to be a costly exercise, although expense is inevitably incurred both locally for collection of data and centrally for downloading, merging, and validating data. Trusts have to face an initial outlay on dedicated software to perform the necessary analyses and the employment of a dedicated person to ensure that the data are complete and accurate. Surprisingly, some trusts remain reluctant to make this relatively small investment, which leaves them ignorant of a complex corporate product and vulnerable at several levels.

When outcomes are open to public scrutiny, data validation is a vital component of meaningful clinical audit. To be effective this necessitates independent and external review, which our society is exploring. But this costs money which small specialty groups do not have.

The society's adult cardiac surgical database report for 1998 is being released as a public document in July. ${ }^{3}$ It outlines in greater detail the progress and problems in cardiac surgical audit.

Bruce E Keogh Secretary B.E.KEOGH@bham.ac.uk Jules Dussek President

Leslie Hamilton Paediatric cardiac surgeom standards of care committee

Society of Cardiothoracic Surgeons of Great Britain and Ireland, c/o Concorde Services, London W12 9RT

1 Shortis M, Winkler E. More on the Bristol affair. BMJ 1998;318:1011. (10 April.)

2 Keogh BE, Dussek J, Watson D, Magee P, Wheatley D. Public confidence and cardiac surgical outcome. BMJ 1998;316:1759-60.

3 Keogh B, Kinsman R. The Society of Cardiothoracic Surgeons of Great Britain and Ireland. 1998 national adult cardiac surgical database report. London: Society of Cardiothoracic Surgeons of Great Britain and Northern Ireland, 1999.

\section{Cooperative language in consultations by male and female doctors}

\section{Paper can be interpreted in two ways} depending on reader's viewpoint

EDIToR-In their descriptive study of cooperative language by male and female doctors Skelton and Hobbs show that communication style does not differ with respect to gender. ${ }^{1}$ They conclude nevertheless that men have more to learn to achieve competence as professional communicators.

I suspect that their assertion is rooted more in the assumptions of gender stereotypes than in hard evidence. For example, the claim that men dominate talk between men and women is based on a few very small studies. The most persuasive of these, by Zimmerman and West, had conversations from only 11 male-female pairs. ${ }^{2}$ The claim that men dominate speech even in the presence of female superiors is supported by an even smaller study, which looked at conversations taped for 14-30 minutes but with only a two minute random extract analysed. ${ }^{3}$ The results were not impressive, and the study's authors said that larger studies were needed to confirm their findings.

As found in the review cited in Skelton and Hobbs's paper, ${ }^{4}$ such small studies yield weak conclusions hedged by words such as "suggest," "tend," "seem," and "generally." For example, "women tend to organise their talk cooperatively, while men tend to organise their talk competitively." Very quickly, these words are dropped and vague trends evolve 
into fossilised dogma (especially if the researcher has an agenda). This is illustrated by an example from the same review; in mixed sex groups "it seems that women put far more effort than men into maintaining and facilitating a conversation" becomes, according to Fishman,, ${ }^{34}$ "women have to perform the interactive shitwork." Men are also guilty of this-for example, by labelling women as gossips they have succeeded in trivialising the content of their speech.

Skelton and Hobbs's paper can be interpreted in two ways depending on your viewpoint. If you believe that men's speech style is competitive and not cooperative then this study shows that men as well as women have the capacity for psychological androgynythat they are capable of adopting female speech styles. If you believe that men already have cooperative abilities then this study is confirmatory. In neither case is there evidence that male doctors have more to learn than female doctors to achieve competence as professional communicators. As researchers we must rise above prevailing prejudices or we risk falling into the same trap as the authors and reaching unsupportable conclusions.

T A Roper Senior registrar St James's University Hospital, Leeds LS9 7TF

1 Skelton JR, Hobbs FDR. Descriptive study of cooperative language in primary care consultations by male and female doctors. BMJ 1999;318:576-9. (27 February.)

2 Zimmerman DH, West C. Sex-roles: interruptions and silences in conversation. In: Thorne B, Henley N, eds. Lan silences in conversation. In: Thorne B, Henley N, eds. Language and sex: difference and dominance. Rowley MA

Woods N. Talking shop. In: Coates J, Cameron D, eds. Women in their speech communities. London: Longman, 1989. 4 Coates J. Women, men and language. London: Longman, 1993

\section{Authors' reply}

EDITOR-There can be little doubt that many people have an agenda regarding gender and language: it is this that makes it possible for such clumsy slogans as Fishman's "intellectual shitwork" to become irritatingly famous. ${ }^{1}$ The caricature version of this argument is that the study of women's language is dominated by women who claim that women's language is "better"-or, as we remark more circumspectly in our paper, that gender and language is "a complex field beset by contradictory studies." And it is certainly true that many studies are based on small samples: this is one reason why we rely on Coates's important, scholarly, and agenda free critical overview ${ }^{2}$ and on her summative statements.

Nevertheless, a great deal of language study generally is based on close scrutiny of small samples of text, from which tentative claims are put forward and developed or rejected as interpretations are perceived to be plausible or not. Preliminary studies will normally be hedged-claims will be at the level of suggestion rather than fact. With varying degrees of explicitness, this is the way in which qualitative study proceeds (particularly ethnography, which is one of the main traditions here): when others interpret the same data in similar ways the status of the claim being made strengthens.
Since Latour and Woolgar's work in the $1970 \mathrm{~s}^{3}$ others have also pointed out that the same kind of process happens throughout the sciences and that written versions of science make many different kinds of claim about "truth." What matters to writers and readers is judicious attention to the strength of any claims.

In this respect, Roper's criticism is apparently that we claim that men have "more to learn to achieve competence as professional communicators" and therefore extrapolate from suggestion to fact. But a careful reading of our paper will show that, in a preliminary study where suggestion is appropriate, we are careful not to state any such conclusion as fact; the extrapolation, therefore, is not ours.

J R Skelton Senior lecturer

F D R Hobbs Head of division

Department of Primary Care and General Practice, University of Birmingham, Birmingham B15 2TT j.r.skelton@bham.ac.uk

1 Fishman P. Interaction: the work women do. In: Thorne B, Kramarae C, Henley N, eds. Language, gender and sociel. Rowley, MA: Newbury House, 1983.

Coates J. Women, men and language. London: Longman, 1993.

3 Latour B, Woolgar S. Laboratory life: the social construction of scientific facts. Beverly Hills: Sage, 1979

Skelton JR The representation of to th in academic medt-

cal writing. J Applied Linguistics 1997;18:121-40.

\section{Onset of adolescent eating disorders}

Dieting may be an early sign, rather than a cause, of eating disorder

EDITOR-Patton et al reported a positive association between dieting and the development of eating disorders in adolescents. A causal effect of dieting on the development of these serious psychiatric conditions was implied in the conclusion. We believe, however, that the data presented did not support the suggested causal effect. ${ }^{2}$

Unlike in a randomised clinical trial, in a cohort study the participants select themselves; in this case the exposure of interest was dieting. Participants at risk of developing eating disorders may have been more likely to expose themselves to dieting. To avoid bias the exposed and unexposed participants in a cohort study should be similar for other important determinants of outcome. ${ }^{3}$ There is no evidence that this was true in this study. In fact, after adjustment for psychiatric disorders at baseline the hazard ratio of severe dieting decreased threefold, which suggests that the exposed and unexposed groups differed for other, unadjusted, factors.

In a cohort study the participants must be free of the disease at inclusion. ${ }^{3}$ Although the 37 incident cases may not have displayed, at baseline, all the signs necessary for the diagnosis of an eating disorder, some of those who were on a diet at the beginning of the study may actually have been in the early stages of an eating disorder; dieting might be an early, non-specific sign of later development of eating disorders and not a cause.
Although some of these points were raised in the discussion, the conclusion and key messages emphasised that adolescents who diet are at increased risk of developing an eating disorder. We agree that inappropriate dietary behaviours should be discouraged; given the global epidemic of obesity, the importance of promoting a healthy lifestyle, including weight control by a reasonable diet and exercise, should be emphasised for all adolescents.

Nicolas Stettler Nutrition fellow nstettle@cceb.med.upenn.edu Andrew M Tershakovec Associate professor of paediatrics

Department of Gastroenterology and Nutrition, Children's Hospital of Philadelphia, 34th Street and Civic Center Boulevard, Philadelphia, PA 19104-4399, USA

Mary B Leonard Assistant professor of paediatrics and epidemiology

Center for Clinical Epidemiology and Biostatistics,

University of Pennsylvania, 423 Guardian Drive, Philadelphia, PA 19104-6021, USA

1 Patton GC, Selzer R, Coffey C, Carlin JB, Wolfe R. Onset of adolescent eating disorders: population based cohort
study over 3 years. BMJ 1999;318:765-8. (20 March.)

2 Evans AS. Causation and disease: the Henle-Koch postulates revisited. Yale Journal of Biology and Medicine 1976;49:175-95

3 Levine M, Walter S, Lee H, Haines T, Holbrook A, Moyer V for Evidence-Based Medicine Working Group. Users' guides to the medical literature. IV. How to use an article about harm. JAMA 1994;271:1615-9

\section{Author's reply}

EDITOR-Despite the inevitable problems of measuring and adjusting for confounding the cohort study is often the only epidemiological tool available for the study of causal associations. Our analyses adjusted for a broad range of confounding factors that we believe are the most relevant to the outcome of eating disorder. These included antecedent weight, mental health state, exercise, and demographic characteristics. Mental health state is particularly important given the view that self concept and self esteem are important antecedents of dieting. Adjusting for these confounders did reduce the level of association with dieting, but it remained strong.

In some instances antecedent dieting may indeed represent the early stages of an eating disorder. But arguing that dieting represents an early stage of eating disorder is untenable as it would mean classifying close to $70 \%$ of female adolescents as having incipient eating disorder. We would agree, though, that further work is needed to delineate the characteristics of dieters and dietary regimens that most predispose to eating disorders.

In an earlier paper we have described some features of the epidemiology of adolescent dieting in an Australian community sample. ${ }^{1}$ Severe dieters were characterised by higher levels of mental health problems, a feature they share with young women with eating disorders. This was not true for the intermediate dieting group, among whom most of the new cases of eating disorder in our recent study arose and for whom dieting was largely determined by weight-even though the body mass index of most young female dieters was in fact within the normal range. 
The broader context that Stettler et al raise-the epidemic of obesity-is crucially important. The message we seek to give is similar: that lifestyle changes that include regular exercise and maintaining a reasonable diet are the least risky options. The challenge is to present a clear and coherent view of what constitutes a reasonable weight and a reasonable diet, in the face of a continuing media barrage of bodily images and dietary programmes that are unsustainable for most adolescents.

\section{G C Patton Professor}

Centre for Adolescent Health, Department of Paediatrics, University of Melbourne, Parkville Victoria 3052, Australia

patton@cryptic

1 Patton GC, Carlin JB, Shao Q, Hibbert ME, Rosier M, Selzer R, et al. Adolescent dieting: health weight control or borderline eating disorder? I Child Psychol Psychiatry 197;38:299-306.

\section{Job applications could be electronic}

EDITOR-I have been working in Asia for five years and, planning a return to the United Kingdom, I began perusing the classified advertisement section of the $B M J$ on the internet, looking for a suitable position. I was pleased to see that the classified section continues to be an excellent resource for medical recruitment.

One thing struck me as strange. So far I have read over one hundred advertisements for anaesthesia positions-and not one had an email address to which to send a job application and curriculum vitae. Nor have I seen a hospital or NHS trust website mentioned in an advertisement. Most ask the candidate to post a curriculum vitae, together with the names and addresses of three referees; several still want up to 12 copies. The contrast in Asia is amazing-it is possible to apply for most medical jobs without ever sending a piece of paper. All the "paperwork" is sent by email and information about the particular hospital department can be found on a website. My last job interview was even conducted using video conferencing.

I am sure that every clinical department and medical personnel department in the United Kingdom has access to a computer. The software for sending emails and accessing the internet can be obtained free of charge. Modems are relatively inexpensive. Submitted curriculum vitae can be circulated by email to all the people on the appointments committee. References can be obtained from the other side of the world within 24 hours using email. Savings on postage, paper, and time can be made. As a journal that is now available on the internet, perhaps the $B M J$ could encourage the use of electronic resources in medical recruitment by asking job advertisers to include an email address in their advertisements.

Graeme M Sanders Senior medical officer Department of Anaesthesiology and Intensive Care, Alice Ho Miu Ling Nethersole Hospital, Hong Kong

\section{Sponsored trials do not necessarily give more-favourable results}

EDIToR-Wahlbeck and Adams report a review of randomised studies comparing clozapine with other antipsychotic drugs in schizophrenia. ${ }^{1}$ They argue that trials that reported some connection with the manufacturer of clozapine (sponsored trials) were associated with more-favourable outcomes for the drug than were trials in which no such connection could be discerned (nonsponsored trials). Unfortunately, the information that the authors present does not support their claims.

The authors state that in sponsored trials the odds of relapsing while taking clozapine are clearly less than the odds of relapsing while taking its comparators (odds ratio 0.5 (95\% confidence interval 0.3 to $0.7)$ ) but that the non-sponsored studies had equivocal findings (odds ratio 0.4 (0.1 to 1.4)). But an unequivocal difference in the sponsored trials and an equivocal difference in the unsponsored trials does not establish a difference between the two types of study. To claim that it does amounts to comparing subgroups on the basis of their $\mathrm{P}$ values, and this is known to be flawed. ${ }^{2}$

The confidence intervals show that the odds of relapse while taking clozapine relative to its comparators lie within wide confidence intervals for both sponsored and unsponsored trials; the data are compatible with the effect of clozapine being the same in both types of trial. A formal assessment would entail calculating the ratio of the odds ratios $(0.5 / 0.4=1.25)$ and constructing a $95 \%$ confidence interval for this quantity (approximately 0.3 to 5.0 ). This shows that there could be considerable differences in either direction in the effects found in the two types of trial but certainly does not establish that there is a difference between them. Similar comments apply when the outcome is clinical improvement or early withdrawal.

J N S Matthews Professor of medical statistics Department of Statistics, University of Newcastle, Newcastle upon Tyne NE1 7RU

j.n.s.matthews@ncl.ac.uk

Competing interests: Professor Matthews has no conflict of interest to declare; in particular he has no connection with, and receives no support from, any pharmaceutical company. 1 Wahlbeck K, Adams C. Sponsored drug trials show more-
favourable outcomes. BMJ 1999;318:465. (13 February.)
2 Matthews JNS, Altman DG. Interaction 2: compare effect
sizes not P values. BMJ 1996;313:808.

\section{Patients must be told of unintended injuries during treatment}

EDITOR-Hingorani et al state that doctors are not legally obliged to provide patients with an explanation after an adverse event. ${ }^{1}$ This may be so in the United Kingdom but is not so in Canada. For example, the case of Stamos $v$ Davies concerned a physician who, in attempting a lung biopsy, hit the patient's spleen. ${ }^{2}$ When asked by the patient what he got he replied, "Something else." Judge Krever found that, in not being candid with his patient, the doctor breached a professional duty. The underlying cause of both the misadventure and the litigation was, in the judge's eyes, the "less than satisfactory physician-patient relationship arising out of the failure on the part of the physician to take the patient into his confidence."

This perspective has been applied in other cases. In one case a physician incurred an extra \$C40 000 ( $\$ 92000)$ against him because he failed to tell a patient that his back operation had been done improperly. ${ }^{3}$

The weight of legal and ethical opinion favours honest disclosure by physicians to patients when misadventure happens. Patients are sometimes less likely to sue if given such information. Even if the misadventure is not the result of negligence an independent cause of complaint will arise if, in not being told about the mishap, the patient suffers further injury.

Ethically, if patients are due relevant information before a procedure takes place, they are certainly due information after the procedure about what happened. ${ }^{4}$ While practitioners might be concerned that this might cause patients anxiety, it should not be their job to protect patients from such anxieties. Told sensitively and with care, patients are capable of taking in even the most difficult news. ${ }^{5}$

Anyone can make a mistake in medicine, but not everyone takes the patient into his or her confidence. The evidence suggests that they ought to do so.

\section{Philip C Hebert Assistant professor}

Department of Family and Community Medicine, University of Toronto, Sunnybrook Health Science Centre, Toronto, ON, Canada

philip.hebert@utoronto.ca

1 Hingorani N, Wong T, Vafidis G. Patients' and doctors' attitudes to amount of information given after unintended injury during treatment: cross sectional, questionnaire survey. BMJ 1999;318:640-1. (6 March.)

2 Stamos v Davies [1985] Ontario High Court 21 DLR 507-10.

3 Gerula v Flores [1995] 126 DLR:507-30.

4 Robertson G. Fraudulent concealment and the duty to disclose medical mistakes. Alberta Law Rev 1987;25:215-23.

5 Hebert PC. Doing right: a practical guide to ethics for physicians and medical trainees. Toronto: Oxford University Press, 1996:82

\section{Politicians may not have same goals as clinicians with regard to mergers}

EDITOR-Garside's editorial on evidence based mergers confuses outcomes and process. ${ }^{1}$ She wants to collect evidence on "how to manage the process of merging" as well as to assemble "evidence on the benefits of NHS merged organisations."

International evidence on the benefits of mergers and the influence of hospital size on the quality of, cost of, and access to care has been extensively reviewed by the NHS Centre for Reviews and Dissemination ${ }^{23}$ and published in a book. ${ }^{4}$ This indicates that 
(a) unit costs fall little beyond 600 beds; (b) quality (in terms of mortality) can sometimes, but may not always, be improved by increased volume; and $(c)$ concentrating services increases travel costs for patients and carers, affecting access and use differentially in terms of social class. In the United States merger mania is largely the product of "an oligarchy of executives who are reacting to the vicissitudes of the market place." Policymakers in the United Kingdom may also use service reconfigurations as a smokescreen behind which to reduce numbers of beds.

The best way to judge the process of merging is surely in relation to cost, quality, and access: do mergers produce better outcomes in these three respects? Of course, these may not be the goals of politicians, who may use mergers as crude methods for disciplining obdurate clinicians, and weak managers who fail to control NHS resources efficiently.

What is needed with mergers is surely a clear statement of goals and predicted outcomes with performance monitored openly by the Audit Commission. Only then can we augment the evidence base and distinguish between political wheezes and the wise use of scarce NHS resources.

Trevor Sheldon Director

tas5@york.ac.uk

Alan Maynard Director

Health Policy Group, University of York, York YO10 5DD

1 Garside P. Evidence based mergers? BMJ 1999;318:345-6 (6 February.)

2 Volume and health care outcomes, costs and patient access. Effective Health Care 1996;2(8)1-12.

3 NHS Centre for Reviews and Dissemination. Concentration and choice in the provision of hospital services. York: University of York, 1997. (CRD report No 8.)

4 Ferguson B, Sheldon T, Posnett J. Concentration and choice in healthcare. Sondon: Royal Society of Medicine Press, 1997.

5 Kassirer JP Mern. Royal Soc Kassirer JP. Mergers and acquisitions: Who benefits? Who
loses? N Engl J Med 1996;334:722-3.

\section{Views on rationing of treatments for erectile dysfunction are mixed}

EdITOR-As the Department of Health consults on the NHS use of treatments for erectile dysfunction ${ }^{1}$ we sought the views of the general practitioners and members of a health panel in South Staffordshire.

The health panel is made up of members of the public who have agreed to be consulted on health issues. As a self selected group they are not statistically representative of the South Staffordshire population; we believe, however, that their views will be of interest. Altogether 194 out of $240(81 \%)$ responded to a questionnaire that had been previously piloted with a focus group. A similar questionnaire was sent to all 291 general practitioners in South Staffordshire; $132(45 \%)$ responded. The table shows the responses to some of the questions.

Most general practitioners and members of the health panel wished to see treatments for erectile dysfunction available on the NHS, although they clearly recognised

Numbers (percentages) of members of health panel and general practitioners (GPs) responding to questions on whether treatment for erectile dysfunction should be available on NHS

\begin{tabular}{|c|c|c|}
\hline & Health panel & GPs \\
\hline \multicolumn{3}{|c|}{ Should treatment for erectile dysfunction be available on the NHS? } \\
\hline No responding to question & 194 & 132 \\
\hline Yes & $67(35)$ & $96(73)$ \\
\hline Depends on patient's condition & $114(59)$ & - \\
\hline No & $13(7)$ & $36(27)$ \\
\hline \multicolumn{3}{|c|}{ How high a priority should these treatments be for the NHS? } \\
\hline No responding to question & 131 & 130 \\
\hline Low & $51(39)$ & $77(59)$ \\
\hline Medium & $61(47)$ & $47(36)$ \\
\hline High & $19(15)$ & $6(5)$ \\
\hline \multicolumn{3}{|c|}{ Should treatments only be prescribed to men who are impotent as a result of an organic (medical) problem? } \\
\hline No responding to question & 193 & 96 \\
\hline Yes & $84(44)$ & $47(49)$ \\
\hline No & $100(51)$ & $49(51)$ \\
\hline Don’t know & $9(5)$ & - \\
\hline \multicolumn{3}{|c|}{ Do you believe treatments for erectile dysfunction should only be prescribed for men below a certain age? } \\
\hline No responding to question & 190 & 96 \\
\hline Yes & $70(37)$ & $23(24)$ \\
\hline No & $107(56)$ & $73(76)$ \\
\hline Don’t know & $13(7)$ & - \\
\hline \multicolumn{3}{|c|}{ Do you believe the number of treatments should be limited? } \\
\hline No responding to question & 185 & 94 \\
\hline Yes & $125(67)$ & $74(79)$ \\
\hline No & 35 (19) & $20(21)$ \\
\hline Don't know & $25(14)$ & - \\
\hline
\end{tabular}

that the number of treatments should be limited; many respondents thought that such treatments should be available only for certain indications. Most respondents thought that erectile dysfunction was a low priority for treatment on the NHS.

The government has finally admitted to a need to ration treatment on the NHS. ${ }^{2} \mathrm{~A}$ rationing decision is a complex mixture of effectiveness and value for money that needs openness. Our survey shows that both the public and professionals have mixed views; justifying selective prescribing is likely be difficult.

Genine Riley Pharmaceutical adviser Genine.Riley@btinternet.com Jonathan Howell Consultant in public health South Staffordshire Health Authority, Stafford ST16 3SR

1 Department of Health. Viagra: NHS prescription proposal. announced. London: Department of Health, 1999. (Press release 21 January.)

2 Chisholm J. Viagra: a botched test case for rationing. BMJ 1999;318:273-4. (30 January.)

\section{Doctors can benefit from spending time with their dying patients}

Editor-Haas's observation that few junior doctors witness peaceful expected death mirrors my own experience in a district general hospital. ${ }^{1}$ I am frequently involved in both suggesting and confirming that a patient is dying and then advising on suitable care and drug treatment to achieve a comfortable death.

I always encourage junior doctors to spend time with a patient they say they can do no more for. A daily contact that shows genuine concern for the patient, often achieved by simply listening, goes a long way; it does not have to be long. Similarly, going back to a patient who has required treatment for terminal restlessness or other symptoms and who has now settled and is dying peacefully is also not done enough. Of course doctors are busy, but they miss a valuable opportunity to see a comfortable death. It is sad if they see their dying patients only when nursing staff call them to adjust drug treatment-a reactive rather than a proactive response.

Haas also talks about the difficulty that doctors may have in recognising that a patient is dying if they see only sudden deaths. Rarely in my experience is impending death confirmed by the medical team. They allude to it by stating that the patient is not for resuscitation or is for tender loving care. I do not think I have ever seen written in the medical notes: "this patient is dying and therefore the care is ...." Why is it still so difficult for doctors to write openly that their patient is dying? Death is not a failure but another phase in a patient's life, which merits just as much attention as when he or she is receiving active treatment.

Patients often know that they are dying and, in my experience, may want to talk about this. Issues such as where they want to die plus unfinished business may be addressed if the healthcare team members support patients at this time rather than isolate themselves in a conspiracy of silence. We can learn much about ourselves as well as about what patients want if we can be brave enough to lower our barriers at these times. The opportunity is missed if doctors and nurses avoid their dying patients. More 
importantly, patients do not have another opportunity at this crucial time.

Sally Mirando Palliative care nurse specialist Nevill Hall Hospital, Abergavenny, Gwent NP7 7EG UMirando@aol.com

1 Haas F. Doctors don't see enough peaceful deaths. $B M$ J 1999;318:264. (23 January.)

\section{Spacer devices increase dose of} inhaled corticosteroids delivered

EDITOR-In their editorial O'Callaghan and Barry highlight several important points regarding the use of inhaled corticosteroids. ${ }^{1}$ We wish to clarify two important statements that they make.

It is incorrect to state that use of a spacer device with a pressurised metered dose inhaler does not affect the dose delivered to the airway. In vitro data showed that a 750 $\mathrm{ml}$ spacer device (Nebuhaler) increased the respirable fraction of budesonide (as a percentage of the nominal dose from the valve) from $8 \%$ to $27 \%$ when an anatomical child throat was used and from 20\% to $40 \%$ when an anatomical adult throat was used. ${ }^{2}$ In vivo work in healthy adults showed that pulmonary bioavailability was increased from $18 \%$ to $36 \%$ when a large volume spacer device was used with a budesonide pressurised metered dose inhaler. ${ }^{3}$

O'Callaghan and Barry imply that use of a spacer device is associated with a reduction in suppression of the hypothalamopituitaryadrenal axis. This may be the case for beclomethasone because of its low hepatic first pass metabolism for the swallowed fraction $(60-70 \%)$ but should not be extrapolated to corticosteroids such as budesonide $(90 \%)$ or fluticasone $(99 \%)$.

Systemic bioactivity is determined by the sum of oral and lung bioavailability. For corticosteroids with a high hepatic first pass metabolism, total bioavailability is determined primarily by lung absorption. ${ }^{4}$ The twofold greater lung delivery afforded by use of a spacer device will therefore translate into a similar increase in systemic bioactivity and potential for adverse systemic effects. Toogood et al showed that adding a large volume spacer device to a budesonide pressurised metered dose inhaler produced a twofold increase in the potency ratio for antiasthmatic efficacy, which was mirrored by a similar increase in the potency ratio for systemic bioactivity. ${ }^{5}$ We recently found that adrenal suppression with a fluticasone pressurised metered dose inhaler is increased twofold when a large volume spacer device is used (unpublished data). Use of a spacer device may represent a two edged sword in terms of determining the overall therapeutic ratio.

Owen J Dempsey Clinical research fellow o.dempsey@dundee.ac.uk

Andrew M Wilson Clinical lecturer

Brian J Lipworth Professor of allergy and respiratory medicine

Department of Clinical Pharmacology and Therapeutics, Ninewells Hospital and Medical School, Dundee DD1 9SY
1 O'Callaghan C, Barry P. Delivering inhaled corticosteroids to patients. BMJ 1999;318:410-1. (13 February.)

2 Berg E. In vitro properties of pressurized metered dose inhalers with and without spacer devices. J Aerosol Med 1995;8(suppl 3):3-11.

3 Thorsson L, Edsbacker S. Lung deposition of budesonide from a pressurized metered-dose inhaler attached to a spacer. Eur Respir J 1998;12:1340-5.

4 Lipworth BJ. Pharmacokinetics of inhaled drugs. Br J Clin Pharmacol 1996:42:697-705.

5 Toogood JH Ba 5 Toogood JH, Baskerville J, Jennings B, Lefcoe NM, Johanstreatment of asthma. Am Rev Respir Dis 1984;129:723-9.

\section{Needs of patients with learning disabilities are not being met}

EDIToR-Aspray et al are right to warn of the risk of "community chaos" in the management of patients with learning disabilities. ${ }^{1}$ We are a small practice with 31 such patients. Our practice has acquired a reputation for offering a caring approach to these patients, so we have tended to attract patients, often from outside our practice area. Difficulties in finding practices willing to register patients with learning disabilities have been reported to us. Patients often find it difficult to access the full range of primary care services. For example, at one practice patients with learning disabilities were discouraged from attending the surgery because of the distress caused to other patients in the waiting room and were instead required to have home visits, which is in conflict with the greater aim of community integration.

Nothing in our education and training had prepared us for the problems we face in delivering care. These patients often have complex behavioural problems that make routine assessment difficult. For example, a patient with a severe learning disability who is on lithium requires sedation for the venepuncture that is necessary to monitor concentrations of the drug. Practices face particular problems in prescribing since many patients often begin treatment on new and unfamiliar drugs in secondary care.

Infection control is also an issue, for both patients and staff, particularly with the high incidence of previous hepatitis B infection among patients with learning disabilities. We have developed a protocol for hepatitis B that we would be happy to share.

Routine health promotion is also a problem. We came across a woman with Down's syndrome who had been excluded from routine screening mammography without any justification.

Obtaining informed consent from these patients is often difficult.

Despite the extra workload there are no additional resources allocated to primary care. We are developing a service for patients with learning disabilities, which will be led by a practice nurse. We are also seeking to develop and improve links with secondary care providers and community services. Practice staff need training, and accredited courses and qualifications should be developed. The primary care needs of patients with learning disabilities deserve more attention and planning. The newly formed primary care groups may be able to influence this, although it will take time to develop the process since the commissioning of services for patients with learning disabilities is currently outside the remit of the primary care groups and is being retained by health authorities as a specialist function.

Mayur Lakhani Chairman, South Charnwood primary care group

Jean Bates Practice nurse

Highgate Surgery, Sileby, Loughborough

LE12 7UD

mklakhani@aol.com

1 Aspray TJ, Francis RN, Tyrer SP, Quilliam SJ. Patients with Aearning disability in the community $B M J$ 1999:318:476-7. (20 February.)

\section{Ethics of GMC's decision to suspend doctor need to be explained}

EDitor-When I heard that a doctor had been suspended by the General Medical Council for starving to death a patient with dementia I assumed that he had done this against the expressed wishes of the relatives and the implied wishes of the patient. Dyer's news item suggests that neither was the case, and food supplements had to be forced on the patient. ${ }^{1}$ This raises serious questions about the ethics of the General Medical Council's decision, which need to be explained to the profession as soon as possible.

Like most of those working with demented patients, I have always aimed at maintaining the dignity and autonomy of the patient-such that I have taken the same action as this doctor in the past. If I had dementia I might well wish to shorten my life by refusing food, and I do not see that doctors have a right to thwart this. As it is presented, this doctor's only mistake was not to carry his nurses with him-an error, but much less than that of allowing the staff to humiliate his patient.

J M Kellett Retired consultant

St George's Hospital Medical School, London SW17 0RE

1 Dyer C. Withdrawal of food supplement judged as misconduct. BMJ 1999;318:895. (3 April.)

\section{Confidence intervals for the number needed to treat}

\section{Pooling numbers needed to treat may not be reliable}

EDITOR-The number needed to treat has become a popular summary statistic for the results of randomised controlled trials because it combines the treatment effect with the background level of risk in the population studied. Patients in a single trial are randomised for both of these factors, and a confidence interval can be calculated which estimates the statistical uncertainty of the number needed to treat in this particular population. ${ }^{1}$

Problems arise when comparisons are made between numbers needed to treat from different randomised trials, or when 
the numbers needed to treat from several trials are combined in a meta-analysis. Often the background level of risk varies between trials in a non-random fashion, depending on the entry criteria in each trial. If the relative benefit of the treatment is constant across these background levels of risk then the number needed to treat in each trial will decrease as the severity of the condition of patients included in the trial rises.

Pooling numbers needed to treat may not give a reliable answer in these circumstances, as the entry criteria of each trial will confound the treatment effect. The meaning of a confidence interval around a pooled number needed to treat poses difficulties when the background level of risk among trials varies widely. I would therefore support Egger et al's suggestion that the pooled results of metaanalyses are reported in terms of a summary statistic which describes the relative benefit of a treatment (such as relative risk). ${ }^{2}$ If the pooled relative risk is reported with its confidence interval both can be applied to any chosen control group event rate.

In figure 3 in Altman's paper the pooled relative risk is 0.62 (95\% confidence interval 0.52 to 0.74 ). When the background rate of angina in the group given percutaneous transluminal coronary angioplasty is $28 \%$ (such as found in the German angioplasty bypass surgery investigation (GABI), which included patients with more severe angina) the number needed to treat for coronary artery bypass grafting would be 8.67 (6.87 to 12.67). If the background rate of angina in the percutaneous transluminal coronary angioplasty group is lower (such as the $16 \%$ found in the coronary angioplasty versus bypass revascularisation investigation (CABRI)) then the number needed to treat would be 16.85 (13.34 to 24.63 )

Finally, I would suggest that numbers needed to treat are always accompanied by the control group event rate to which they apply and the relative risk and confidence interval from which they are derived.

Christopher Cates General practitioner Manor View Practice, Bushey, Hertfordshire WD2 2NN

chriscates@email.msn.com

1 Altman DG. Confidence intervals for the number needed to treat. BMJ 1998;317:1309-12. (7 November.)

2 Egger M, Davey Smith G, Phillips A. Meta-analysis: principles and procedures. BMJ 1997:315:1533-7.

\section{Absolute risk reduction is less likely to be misunderstood}

EDITOR-Altman describes the number needed to treat as a useful way of reporting the results of randomised controlled trials and proceeds to show how confidence intervals for this measure are calculated. ${ }^{1}$ As he shows, however, a confidence interval for an absolute risk reduction from, say, $-5 \%$ to $25 \%$ inverts to a confidence interval that goes from a number needed to treat to benefit of 4 , through infinity, to a number needed to treat to harm of 20. My impression from discussing such intervals with clinicians is that they find them difficult to grasp.

Altman correctly argues on general grounds against presenting confidence inter- vals only for significant effects. Moreover, the potential application in presentations such as forest plots that put together the results of several studies rules out the argument that the number needed to treat should only be estimated when it is significant.

I believe that the number needed to treat has as much potential to confuse as to enlighten. The absolute risk reduction is a more basic quantity, with much less potential to be misunderstood, and should be regarded as the primary measure of effect size. The estimated absolute risk reduction and its confidence interval are most readily grasped when presented in percentages, as in Altman's paper. The number needed to treat and its confidence intervals are better regarded as secondary, whether in the numerical presentation of results or as an additional scale on a diagram-a useful informal alternative way of interpreting an absolute risk reduction when it is well away from zero.

Robert G Newcombe Senior lecturer in medical statistics

University of Wales College of Medicine, Cardiff CF4 4XN

1 Altman DG. Confidence intervals for the number needed to treat. $B M J$ 1998;317:1309-12. (7 November.)

\section{Assessment of competence to complete advance directives}

Standardised instruments are needed to guide the measurement of competence

EDITOR-Fazel et al described an instrument for the assessment of competency to complete advance directives that seems to be reliable, valid, and ready for use in clinical practice. ${ }^{1}$ We believe, however, that certain aspects require clarification before the clinical usefulness of the test is assured.

Firstly, who is this test meant for? Different groups are suggested in different parts of the text. Is it meant to differentiate between competency and incompetency in demented patients, in the broader group of patient with cognitive impairment, or in elderly volunteers? If the test aims to assess competency in dementia, test-retest analysis should include only data on demented patients, because fluctuations in functioning in this group are more common. The reported test-retest correlation was mainly based on data on non-demented subjects, and there is a likelihood of overestimation of the reliability of the test for demented subjects.

The test discriminated between nondemented volunteers and demented participants, but the influence of education on the results was not considered. Volunteers are often well educated, so the results may reflect differences in educational background instead of differences in competence.

Finally, and probably most importantly, the gold standard and test result were not independently obtained in the present study, and therefore the test could be considered as having only face validity. Use of this gold standard for the calculation of a cut-off score and the fact that it was based on only 19 (including eight non-demented) subjects necessitate further development considering the huge consequences that the application of this test could have in clinical practice. This may also apply to shortening the test by using two instead of three vignettes without checking its effect on the reliability of the test result.

In conclusion, there is a critical need for standardised instruments to guide the measurement of competence in many domains, including consent to treatment, engaging in research, and making choices about living arrangements. Fazel et al's study is a welcome initial step.

Saskia Teunise Senior psychologist, psychology department, community mental health unit

Steunisse@boreas.clara.net

Sarah Eagger Senior lecturer in old age psychiatry

James Warner Senior lecturer in old age psychiatry

St Charles Hospital, Exmoor Street, London

W10 6DZ

1 Fazel S, Hope T, Jacoby R. Assessment of competence to complete advance directives: validation of a patien centred approach. BMJ 1999;318:493-7. (20 February.)

\section{Authors' reply}

EDITOR-We believe that the instrument we have described to assess competence to complete advance directives can be used on anyone, including healthy elderly people and those with mild dementia. We argue in the paper that it would seem worthwhile for advance directives to be completed at a time when people already have some disease or disability, and those with dementia could therefore be the largest group for whom an advance directive is relevant. Nevertheless, in palliative care and oncology there will be adults for whom assessments of competence to complete advance directives are required.

Teunisse et al ask whether we considered the influence of education. It was tested with the national adult reading test, a valid and reliable index of premorbid intelligence. ${ }^{1} \mathrm{We}$ found no significant difference in the mean scores on the national adult reading test between the elderly volunteers (predicted IQ 101.0 (SD 14.5)) and patients with dementia (predicted IQ 96.8 (17.2)).

The authors' final point concerns the validity of the instrument. Our results go beyond face validity in that the gold standard was conducted by two old age psychiatrists; they had not conducted the initial interview and therefore did not know the score that the participant had received on the competence instrument. As the authors say, further work refining this and other instruments would be worthwhile.

Seena Fazel Wellcome research registrar seena.fazel@psychiatry.oxford.ac.uk

Tony Hope Reader in medicine

Robin Jacoby Professor of old age psychiatry

Section of Old Age Psychiatry, University of Oxford Department of Psychiatry, Warneford Hospital, Oxford OX3 7JX

1 O'Carroll R. The assessment of premorbid ability: a critical review. Neurocase 1995;1:83-9. 


\section{Role of the routine neonatal examination}

It probably makes more sense for other staff to carry out neonatal examinations

EDITOR-As a senior house officer in a neonatal unit with over 7000 births a year, I can confirm Hall's remarks that needless delays in the discharge of mothers and their babies occur due to heavy workload. ${ }^{1}$ My crude, hurriedly acquired examination skills often act as a front and do little to reassure me that all is well with the child I am examining. Inquiries about feeding, the behaviour of the child, and even the contents of the child's nappies give me greatest confidence in my clinical decision making.

Most valuable time during neonatal checks is spent talking about educational aspects of child care and what a new mother can expect from her child in the coming weeks. I believe that medical examination can be carried out by a midwife, with positive advantages for mother and child. The established relationship between midwife, mother, and child should be built on to create a seamless flow of reassuring advice; the clinical examination would be seen as part of that process and not a separate issue. Where high sensitivity and specificity exist for parts of the clinical examination, protocols should continue to be used to ensure correct management.

Having witnessed the successful contribution made by advanced neonatal nurse practitioners in the unit in which I work, I believe that clinical examination skills, if properly taught, can be undertaken by other medical staff; doctors should not regard this as a challenge to their position. If neonatal examination is recognised as a blunt tool in the screening for childhood diseases then we should not be afraid to redefine our goals and alter our clinical practice to ensure a better quality of care and education.

David Walker Senior house officer

Neonatal Medicine Department, Women's Centre, John Radcliffe Hospital, Oxford OX3 9DU

DFCAD@aol.com

1 Hall DMB. The role of the routine neonatal examination. BMJ 1999;318:619-20. (6 March.)

\section{Broader criteria should be used to} evaluate the role of neonatal examination EDITOR-Hall ${ }^{1}$ concluded from the paper by Glazener et $\mathrm{al}^{2}$ that having two routine neonatal examinations is no better than having one. Three issues must be considered.

Firstly, the conclusion was partly based on Glazener et al's findings that, although more babies who were examined twice attended orthopaedic outpatient clinics for suspected congenital dislocation of the hip, there was no significant difference in the number of babies who required active management. $^{2}$ In both groups, however, the number requiring active management was small (12 v 15), and the study was unlikely to have sufficient power to detect differences in the outcome between the two groups even if they existed.

Secondly, dysplastic hips which were detected early might have been managed satisfactorily by measures such as double nappies, hence reducing the number of babies requiring active management.

Thirdly, in many countries neonatal examination provides the only opportunity for a paediatrician to detect abnormalities that might otherwise be missed by a general practitioner. Hence a second examination minimises the risk of an important diagnosis being missed.

Applying traditional criteria for good screening tests, Hall also doubted whether neonatal examinations are really useful. But such examinations are different from many screening tests.

Firstly, most parents like to receive either counselling on minor problems or reassurance that their newborn babies are normal. Since the health professionals must examine the baby before such explanations or reassurance can be given and the time taken to perform a proper neonatal examination is probably no more than five minutes, abolishing routine neonatal examinations is unlikely to save much time.

Secondly, neonatal examination may occasionally detect initially unsuspected serious conditions, prompt treatment of which may greatly improve prognosis.

Thirdly, apparently minor abnormalities may indicate serious underlying abnormalities. These may prompt active treatment or close monitoring for the development of complications.

The role of neonatal screening should be evaluated using broader criteria than Wilson and Jungner's criteria for screening. ${ }^{3}$ Much stronger evidence is required to convince the public that an existing neonatal examination programme should be withdrawn than to convince them that a new screening programme should be introduced. The decision to abolish neonatal examinations cannot be taken lightly.

S P Leung Visiting paediatrician

Hong Kong Baptist Hospital, 222 Waterloo Road, Kowloon, Hong Kong

spleung1@netvigator.com

1 Hall DMB. The role of the routine neonatal examination. BMJ 1999;318:619-20. (6 March.)

2 Glazener CMA, Ramsay CR, Campbell MG, Booth P, Duffty P, Lloyd DJ. Neonatal examination and screenin trial (NEST): a randomised, controlled, switchback trial of alternative policies for low risk infants. BMJ 1999:318:62732. (6 March.)

3 Wilson JM, Jungner YG. Principles and practice of mass screening for disease. Bol Oficina Sanit Panam 1968;65. 281-393.

\section{"Health care is a human right" is a meaningless and devastating manifesto}

Editor-"Health care is a human right," declares the Tavistock Group. ${ }^{1}$ If the group accepts the World Health Organisation's definition of health as a "state of complete physical, mental and social well-being" then the demand that the provision of such a state be recognised as a human right will have little meaning.

If the Tavistock Group has an alternative definition of health then it should say so. As long as we are uncertain what the word denotes, "health care" remains a nebulous entity. Whatever the definition of health may be, any lack of it is a consequence of life itself. No one dies healthy. (It could be argued that violence, wars, and accidents may result in the death of people in good health, but none of these fits the requirement of social wellbeing).

Health for all is not attainable. The bulk of money, effort, and thought in health care is spent on prolonging life by managing disease. Most of health work is medical care. Although immortality and universal health are unattainable, we certainly should aim for a healthier world. For this we need peace, a new economic world order, the restoration of the family, and many other things which cannot be classified as medical care. We also need a new socioeconomic philosophy, as capitalism and socialism have both failed to deliver their promises.

Care, in the context of rights, means not attitude but action, and this requires money. Caring has become a business, the biggest business of all, and care in action does work. What the Tavistock Group should say is that everyone has the right to receive help to remain healthy or to regain health or to receive treatment when ill and also help when dying.

Universal, complete health care is unattainable, not only because we live in an unjust world. We now have the technology to manage disease on a large scale. Yet disease management and life prolongation are matters of expenditure. To buy a life expectancy of 90 years may cost a society twice as much as to buy one of 75 years. Eventually society may spend its entire wealth on health or, rather, on survival despite disease. To distribute longevity more evenly would be expensive because to keep unlucky people alive is expensive.

Add to this the fact that at the very time when life expectancy keeps increasing, aging and being old have become unfashionable. The technology to diminish the ravages of age does exist. Has the attribute of the gods to look young forever been made into a human right by manifesto?

Imre J P Loefler Editor, Nairobi Hospital Proceeding Nairobi Hospital, PO Box 47964, Nairobi, Kenya loefler@swiftkenya.com

1 Smith R, Hiatt H, Berwick D, and Tavistock Group. Shared ethical principles for everybody in health care: a working draft from the Tavistock Group BMJ 1999:318:248-51. (23 draft from the lavistock Group. BMJ 1999;318:248-51. (23
January.)

\section{Rapid responses} $e \mathrm{BM}$

Rapid responses submitted directly to our website are available on www.bmj.com 